\title{
Secondary Caries in situ Models: A Systematic Review
}

\author{
Audrey C.C. Hollanders ${ }^{a}$ Nicolien K. Kuper ${ }^{a}$ Tamires T. Maske ${ }^{b}$ \\ Marie-Charlotte D.N.J.M. Huysmans ${ }^{a}$ \\ ${ }^{a}$ Department of Dentistry, Radboud Institute for Health Sciences, Radboud University Medical Center, \\ Nijmegen, The Netherlands; b School of Dentistry, Federal University of Pelotas, Pelotas, Brazil
}

\section{Keywords}

In situ models · Recurrent caries · Secondary caries

\begin{abstract}
In situ caries research serves as a bridge between clinical research and laboratory studies. In this kind of research, volunteers wear a removable intraoral splint or prosthesis containing research samples. Many different in situ models exist to investigate secondary caries. This systematic review compared currently existing secondary caries models and their lesion progression per day values. Materials and Methods: Three databases (Medline, Embase, and Cochrane) were searched for relevant literature. Bias risk was assessed and model parameters and caries-related outcomes were extracted by 2 independent researchers. Where possible, caries-related outcomes were normalized by estimating lesion progression per day by dividing lesion depth extracted from microradiographic or microhardness data by the number of days the study lasted. Results: The literature search identified 335 articles. After eliminating duplicates and selection, 31 articles were included. The models differed greatly on factors such as sample location, presence of fluoride in the model, and analysis methods. Three main groups could be identified by sample placement; $68 \%$ of models placed samples palatally in the upper jaw, and the lower jaw model
\end{abstract}

\begin{tabular}{ll}
\hline KARGER & $\begin{array}{l}\text { (c) } 2018 \text { The Author(s) } \\
\text { Published by S. Karger AG, Basel }\end{array}$ \\
E-Mail karger@karger.com & This article is licensed under the Creative Commons Attribution- \\
www.karger.com/cre & $\begin{array}{l}\text { NonCommercial-NoDerivatives 4.0 International License (CC BY- } \\
\text { NC-ND) (http://www.karger.com/Services/OpenAccessLicense). } \\
\text { Usage and distribution for commercial purposes as well as any dis- } \\
\text { tribution of modified material requires written permission. }\end{array}$
\end{tabular}

could be divided into the buccal (26\%) and approximal (6\%) areas. Average lesion progression in enamel next to composite was $4.3 \pm 2.8 \mu \mathrm{m}$ (range1.1-8.8 $\mu \mathrm{m} /$ day). Discussion: Studies conducted with palatal models showed caries progression rates 2-5 times higher than the estimated clinical progression rates. Lesion progression per day could be a useful tool for future comparison of models and establishing a standardized model.

(c) 2018 The Author(s)

Published by S. Karger AG, Basel

Dental caries is the localized destruction of susceptible dental hard tissues by acidic byproducts from the bacterial fermentation of dietary carbohydrates [Fejerskov and Kidd, 2015]. Primary caries is the term used to describe caries lesions developing on intact, natural tooth surfaces, as opposed to secondary or recurrent caries, which develops next to an existing restoration [Fejerskov and Kidd, 2015]. Two regions have been described when considering the process of secondary caries; the surface lesion, which develops perpendicular to the tooth surface and can be considered a primary lesion developing next to a restoration, and the wall lesion, which develops perpendicular to the tooth/restoration interface (Fig. 1) [Hals and Nernaes, 1971]. Several study types are currently used to investigate secondary caries. These include in vi- 
tro, in situ, and in vivo models [Lynch and ten Cate, 2006; Bernardo et al., 2007; Kuper et al., 2015 ]. To simulate a failed interface between a tooth and a restoration, a gap can be formed between the two during restoration prior to cariogenic challenge.

In an attempt to approximate the clinical situation more closely than in an in vitro model for the purpose of caries research, in situ models are used to investigate secondary caries [Askar et al., 2017]. In in situ studies, a group of volunteers wears an appliance containing dental samples in their mouth. Research conditions can be tested on these samples. The experimental conditions in the various in situ models can differ greatly. Recently, a systematic review evaluated in situ studies in secondary caries [Askar et al., 2017]. It aimed to compare the performance of 7 classes of restorative material based on results from 9 in situ studies. The authors attempted to create a network model displaying the secondary caries susceptibility of several restorative materials. They found, however, that inconsistency was too great to draw clear conclusions. Our review aims to address the inconsistencies in such studies, in an attempt to increase the comparability of studies in the future.

The lesion progression per day of (secondary) caries lesions has been described in in situ studies and could be a valuable way to compare different models [Thomas et al., 2007]. However, the variations in analysis methods of secondary caries formation has led to differences in outcome measures [Kielbassa et al., 2003; Vasconcelos et al., 2014]. Microradiographic techniques are considered the gold standard in the measurement of caries lesions; they provide both lesion depth and mineral loss values [Thomas et al., 2006]. Transversal microradiography (TMR), a microradiographic technique, uses image analysis software to render a mineral concentration profile which is used to calculate lesion depth and integrated mineral loss. Cross-sectional microhardness is also frequently used, comprising microhardness measurements on a cross-section of the surface. As microhardness and mineral volume are related, it is possible to estimate one from the other [Featherstone et al., 1983; Kielbassa et al., 1999b].

Secondary caries lesions are often divided into 2 distinct types, surface and wall lesions (Fig. 1). This review will focus on comparing surface lesion development next to restorative materials, since wall lesion measurement is, as of yet, comparatively rare and has not been standardized. In some cases, wall lesions have been measured perpendicular to the interface [Thomas et al., 2007], but also parallel to the interface [Grossman and Matejka, 1995]. This leads to incomparable results.

Secondary Caries in situ Models

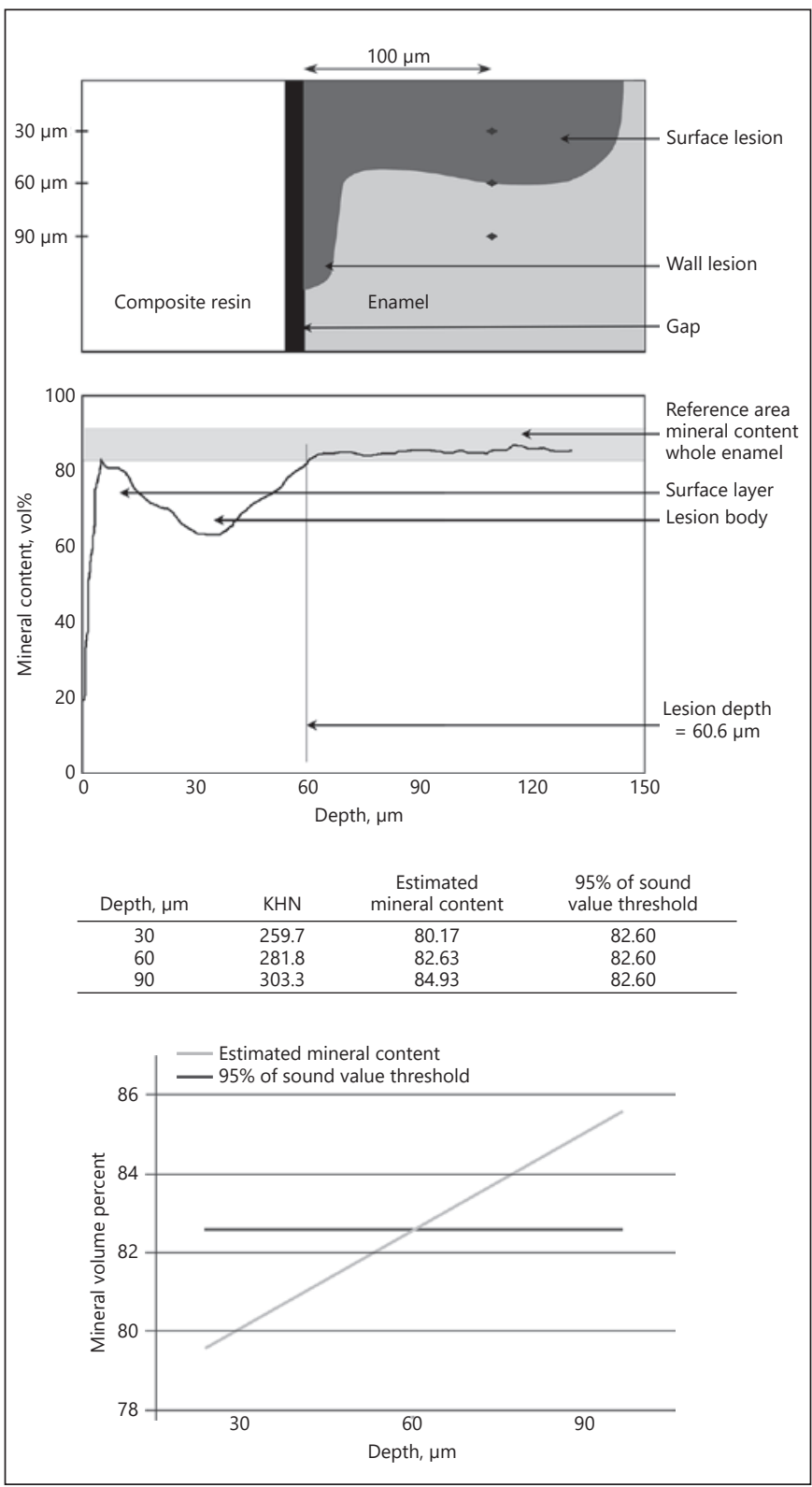

Fig. 1. An example of the lesion depth calculation. The recorded lesion depth in this case was $60.6 \mu \mathrm{m}$ [Chimello et al., 2008a]. $\mathrm{KHN}$, Knoop hardness number; vol\%, volume percent.

Clearly, protocols for in situ studies vary. Our aim was to systematically review in situ models for secondary caries, compare their methodology and parameters, and, where possible, determine a link to the reported lesion progression rate. In line with this, we hoped to come up with recommendations for improving in situ studies and ways to make them more comparable. 


\section{Materials and Methods}

\section{Inclusion Criteria}

- The study should use a removable device containing samples that is worn intra-orally by volunteers.

- These samples should consist of dental tissue (enamel and/or dentin) and a restorative material.

- Dental caries should be allowed to develop while the samples are exposed to the in situ environment.

- The study should have a caries-related outcome, producing measurements such as lesion depth, mineral loss, or microhardness.

Studies describing in vitro or in vivo caries formation or in situ studies investigating primary caries were not included in this review. Studies where caries was formed in vitro but samples were placed in in situ devices afterwards to investigate remineralization were also excluded. Studies that did not measure demineralization, but only considered outcome measures such as microtensile bond strength or biofilm composition were also excluded.

Where possible, outcome measures were translated into lesion progression rates in micrometres per day. In order to be included in the calculations for progression per day, the article had to measure caries progression according to cross-sectional microhardness or microradiography, and report lesion depth or hardness values for a composite group in enamel.

\section{Search Strategy}

The databases Medline, Cochrane, and Embase were searched for relevant articles. The Cochrane database was also searched for ongoing trials. The search strategy was composed of controlled vocabulary and free text words around the terms: "dental caries," "restorative material," "secondary caries," "in situ," and "models." Reference lists of eligible articles were hand-searched in an attempt to detect other potentially eligible studies. There was no limit as to the date or language of the articles. The exact search strategies for both Medline and Embase can be found in online supplementary Appendix 1 (see www.karger.com/doi/10.1159/000487200 for all online suppl. material).

\section{Study Selection}

All retrieved articles were stored in Endnote X7.2 ${ }^{\circledR}$ software (Thomson Reuters, San Francisco, CA, USA). Duplicates were identified and excluded using the software. Two independent examiners (A.C.C.H. and N.K.K.) assessed all studies. The selected studies' titles and abstracts were carefully screened based on the inclusion criteria. If doubt existed based on an article's abstract, the full text version was reviewed. The studies considered eligible were ordered as full-text articles. In case of disagreement, a third reviewer (M.-C.D.N.J.M.H.) decided on eligibility. Inter-examiner reliability about which studies to include was determined by using Cohen's $\kappa$ on the decisions made by both researchers (based on title and abstract).

Data Collection and Risk of Bias Assessment

All included articles had the following data extracted by two independent examiners (A.C.C.H. and T.T.M.): number and age of volunteers; dental status of volunteers; research conditions of the article; study design; location of the samples; method of plaque promotion; the number of weeks the devices were worn; surface lesion depth; enamel/dentin or combined samples; human or bo- vine dental material; the restorative materials used; fluoride in the model; sucrose-dipping conditions; whether the devices were worn during meals; gap methods and sizes; the number of dropouts of volunteers; analysis methods; the number of samples; the results of the study; and caries lesion progression per day in the composite control group in enamel (if possible).

The quality of the studies included was assessed with a tool for assessing the risk of bias, with modifications specific for in situ studies [Centre for Reviews and Dissemination, 2008; The Cochrane Collaboration, 2011]. The risk of bias assessment was carried out by two independent examiners (A.C.C.H. and T.T.M.). We defined a low risk of bias as a low risk of bias for all key domains (a score in our tool of $\leq 3$ ). Average or medium risk of bias was an increased or unclear risk of bias for $\geq 1$ domains, and corresponded with a score of 4-6 points. A high risk of bias was an increased risk of bias for $>1$ domain, and corresponded with a score of $\geq 7$ or more. In cases of disagreement on data collection or risk of bias assessment, a third researcher (N.K.K.) was consulted. The inter-examiner $\kappa$ value was determined for the risk of bias scores in all the articles. Specific information about the tool used for identifying the risk of bias can be found in online supplementary Appendix 2.

\section{Calculation of Surface Lesion Depth from Microhardness}

The data necessary to estimate the lesion progression per day was always extracted from the control composite group in enamel samples, in order to compare similar groups. For articles with lesion depth as an outcome variable, the average lesion depth was extracted and divided by the number of study days.

For articles with microhardness as their outcome variable, the equation: $21.19+3.66 \times \sqrt{\mathrm{KHN}}$, where $\mathrm{KHN}$ is the Knoop hardness number, was used to estimate volume percentage numbers at several depths, all approximately $100 \mu \mathrm{m}$ away from the tooth/restoration interface [Kielbassa et al., 1999b]. A linear relationship was then assumed for the depth and mineral volume percentage. Microradiographic techniques assume that lesion depth is reached where the tooth material reassumes 90 or $95 \%$ of its original mineral volume [Thomas et al., 2006]; $95 \%$ of the original volume of enamel, which is $87 \%$, is $82.6 \%$.

The depth at which the mineral volume of the enamel sample was expected to be $82.6 \%$ was estimated from the assumed linear relationship between depth and mineral volume percentage. This depth was assumed to be the average lesion depth for this study. An example of the lesion depth estimation can be found in Figure 1.

\section{Statistical Analysis of Studies}

Descriptive statistics were used to calculate the frequencies of the factors in comparison with SPSS v22 (IBM, NY, USA). Lesion depths in the models were calculated using Microsoft Office Excel 2007 (Microsoft, Redmond, WA, USA).

\section{Results}

From the 335 titles originally selected, 31 were included in our systematic review. Details of the inclusion process can be found in Figure 2. The inter-examiner agreement for inclusion or exclusion of articles (based on title and abstract), was represented by a Cohen's $\kappa$ value of 0.87 . 
Fig. 2. Search strategy results.

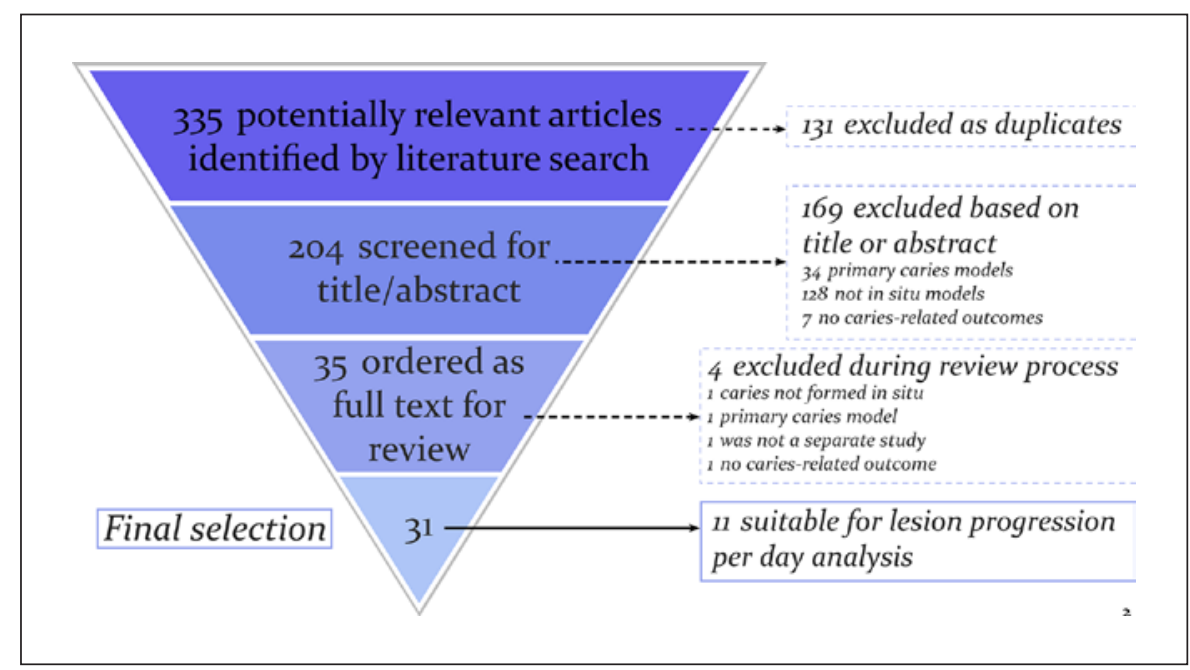

Risk of bias scores per study can be found in online supplementary Appendix 3. Only 3 studies (10\%) received a low risk of bias classification; $23(74 \%)$ received an average risk of bias classification; and $5(16 \%)$ received a high risk of bias classification. The inter-examiner-weighted $\kappa$ value calculated for the risk of bias scores was 0.63.

Table 1 shows an overview of the research topics considered in the studies and how often they occurred. Table 2 shows an overview of all relevant parameters extracted from the included studies.

A split-mouth design was used in the majority of studies (74\%) and a cross-over design in the rest (26\%). Enamel-only samples were used in $52 \%$ of studies, $16 \%$ used dentin samples, and $32 \%$ used samples of dentin and enamel. Both human $(68 \%)$ and bovine $(32 \%)$ tooth materials were used. The restorative materials used varied greatly, but almost every study used at least 1 resin composite.

The in situ appliance design could be divided into 3 main groups: upper jaw appliances with samples placed in a palatal position (68\%), and lower jaw appliances with samples placed either in the buccal flanges $(26 \%)$ or approximally ( $6 \%$, only in edentulous patients). Plaque formation on the samples was promoted by: not brushing the samples (13\%), placing samples in a recessed position (19\%), or, most commonly, using a mesh to cover the samples (68\%). A protocol of dipping the device in sucrose to increase the cariogenic challenge was used in $90 \%$ of the studies. The remaining studies were conducted on (partially) edentulous patients, using the device as a prosthesis. A concentration of $20 \%$ sucrose was mostly used. Eight dippings a day was the most frequently used proto- col ( $61 \%$ of those using a sucrose solution), with 4,6 , or 10 dippings a day being used occasionally.

Fluoride-containing toothpastes were used in $48 \%$ of the studies, and $42 \%$ had their volunteers use fluoridefree toothpaste. The remaining studies did not report the toothpaste used, or the fluoride in toothpaste was a research condition. Only 8 studies out of the 31 reported the fluoride concentration in the drinking water consumed by the participants.

Lesion development was measured using microradiographic techniques (TMR or transversal wavelength independent microradiography [TWIM]) in $36 \%$ of the studies, $48 \%$ used cross-sectional microhardness, and $16 \%$ used other analysis methods, such as quantitative light fluorescence or polarized light microscopy. For studies reporting $>1$ analysis method, the method presented as the main result was considered in this review. Eleven studies could be used to calculate or estimate average lesion progression per day (Table 3). Lesion progression varied between 1.1 and $8.8 \mu \mathrm{m} /$ day. However, 2 main trends could be observed, with 4 studies showing a rate of $\leq 2 \mu \mathrm{m} /$ day and 7 a rate of $>4 \mu \mathrm{m} /$ day. These 7 studies with a high progression rate were all palatal models, used mesh for plaque promotion, and an experiment duration of only 2 weeks.

\section{Discussion}

Parameters of in situ models used to investigate secondary caries varied greatly. Caries-related outcome measures for different dentate models were translated 
Table 1. Research topics of the studies

\begin{tabular}{|c|c|c|}
\hline Research condition & $N$ & Studies \\
\hline $\begin{array}{l}\text { Different restorative or } \\
\text { bonding materials }\end{array}$ & 21 & $\begin{array}{l}\text { Benelli et al., } 1993 \\
\text { Dijkman and Arends, } 1992 \\
\text { Kielbassa et al., } 2003 \\
\text { Kuper et al., } 2014 \\
\text { Melo et al., } 2013 \\
\text { Pinto et al., } 2015 \\
\text { van de Sande et al., } 2014 \\
\text { Cenci et al., } 2008 \\
\text { Jorge et al., 2015 } \\
\text { Kirsten et al., } 2013 \\
\text { Lennon et al., } 2007 \\
\text { Moura et al., 2004 } \\
\text { Pinto et al., 2009 } \\
\text { Vasconcelos et al., } 2014 \\
\text { da Silva et al., } 2010 \\
\text { Kielbassa et al., } 1999 \text { a } \\
\text { Kuper et al., } 2015 \\
\text { Melo et al., } 2014 \\
\text { Paradella et al., } 2008 \\
\text { Sousa et al., } 2009 \\
\text { Wang et al., } 2010\end{array}$ \\
\hline $\begin{array}{l}\text { Degradation or aging of } \\
\text { interfaces }\end{array}$ & 7 & $\begin{array}{l}\text { Barata et al., } 2012 \\
\text { Kuper et al., } 2014 \\
\text { Reinke et al., } 2012 \\
\text { de Moraes et al., } 2016 \\
\text { Lima et al., } 2009 \\
\text { Hara et al., } 2006 \\
\text { Montagner et al., } 2015\end{array}$ \\
\hline Er:YAG laser preparation & 4 & $\begin{array}{l}\text { Chimello et al., 2008a, b } \\
\text { Jorge et al., 2015 } \\
\text { Colucci et al., } 2015\end{array}$ \\
\hline Fluoride toothpaste & 2 & $\begin{array}{l}\text { Cenci et al., } 2008 \\
\text { de Moraes et al., } 2016\end{array}$ \\
\hline $\begin{array}{l}\text { Secondary lesion } \\
\text { progression }\end{array}$ & 1 & Thomas et al., 2007 \\
\hline
\end{tabular}

into values of caries progression per day, which were then compared.

In the studies considered in this review, 3 main possibilities could be identified when it came to sample placement: buccal, palatal, and approximal placements. Approximal placements were only applied in edentulous participants. This makes sense for a practical reason, since space and appliance height are necessary for these placements.

The study design that was chosen depended partially on the research question. Split-mouth designs were the most popular. Studies investigating the influence of a fluoride-containing restorative material often used a cross-over design, though not always. That carry-over does not occur between the left and right side of a palatal model seems to be an assumption shared by research communities; however, this is debatable, since the studies that we included provide insufficient evidence of this [Sousa et al., 2009; Melo et al., 2013, 2014]. More evidence of the absence of a carry-over effect in split-mouth studies needs to be gathered. Cross-over designs are definitely required when a treatment of the whole mouth is studied.

The time it takes for a clinical approximal lesion in the posterior region to progress through the enamel is estimated at 4-6 years [Fejerskov and Kidd, 2015]. The thickness of the enamel in upper and lower premolars lies, on average, between 2.3 and $2.7 \mathrm{~mm}$ [Vellini-Ferreira et al., 2012]. Therefore, the average clinical progression of an approximal lesion is around $0.5 \mathrm{~mm} /$ year. This is equivalent to $1.4 \mu \mathrm{m} /$ day. Despite the facts that this applies to an approximal location, concerns primary caries, and has individual variability, we compared this rate with the progression rates in this review. We observed that some models, mainly with samples in the lower jaw, produced lesion progression rates close to the clinical reference. However, most studies showed rates approximately 4 -fold higher, representing a somewhat "forced" caries formation. The common denominators for these models appear to be: palatal location, plaque promotion with a mesh, and a relatively short experiment duration. As such studies often have a cross-over design requiring multiple experimental periods, a high lesion progression rate may have been aimed for, in order to limit the overall study time. One study with a palatal location and mesh-covered samples showed only low caries progression rates [Benelli et al., 1993]. We speculate that this was related to the fact that they used samples with a natural surface, and not flat polished samples like in the other studies, as this will slow down initial lesion formation.

Converting cross-sectional microhardness values to mineral volume values is controversial, and the best way to do this is so far unclear [Magalhaes et al., 2009]. In general, it should be avoided where possible. In the future, it would be helpful for in situ studies to measure lesion depth microradiographically, in order to minimize doubt and simplify the comparison of different studies.

Both human and bovine tooth materials were used in the included studies. When human tooth material is unavailable or unsuitable, bovine tooth material is the most common substitute [Yassen et al., 2011]. Bovine enamel 


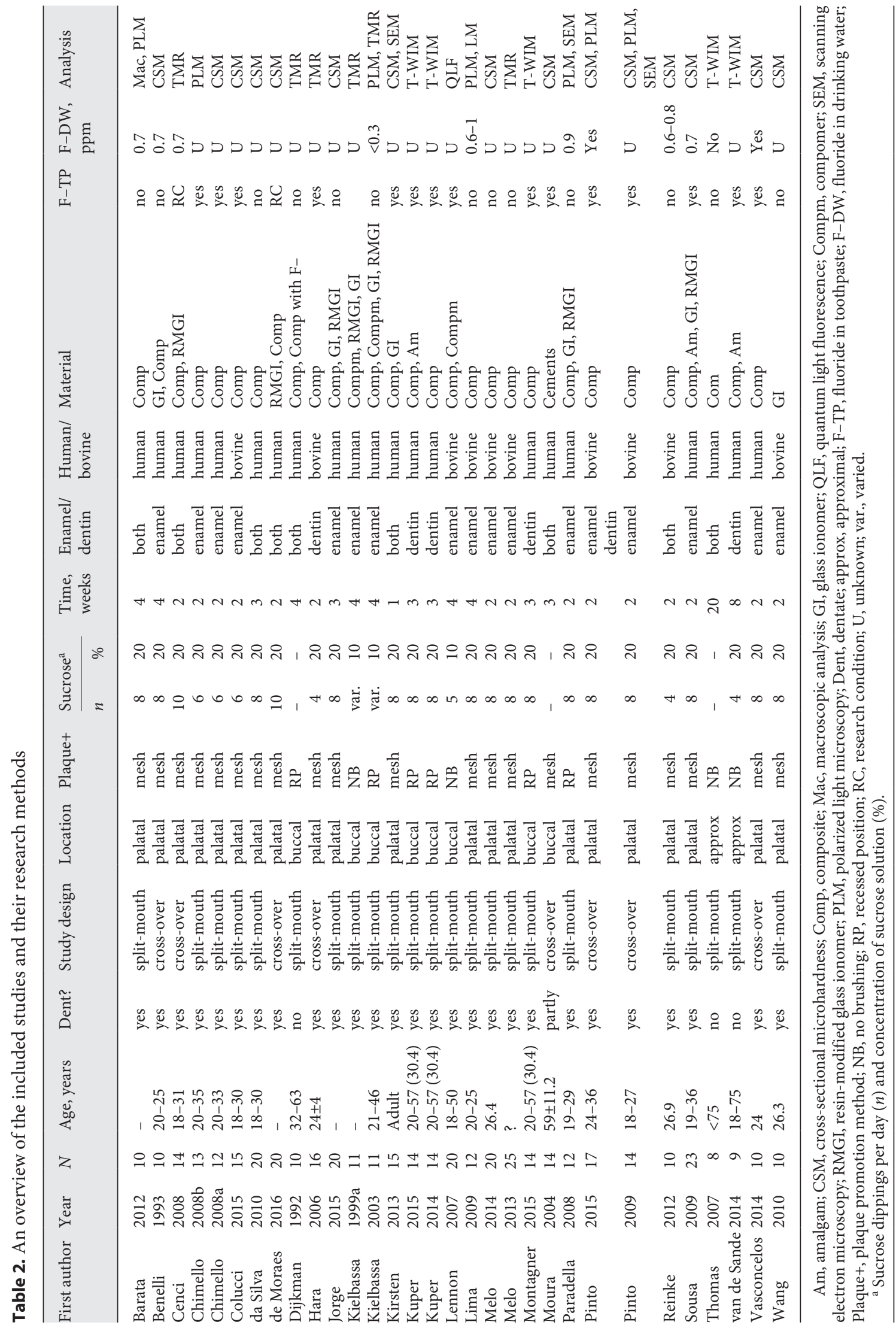


Table 3. Characteristics of the studies for which it was possible to calculate or estimate the lesion progression per day

\begin{tabular}{|c|c|c|c|c|c|c|c|c|c|c|}
\hline \multirow[t]{2}{*}{ First author } & \multirow[t]{2}{*}{ Location } & \multirow[t]{2}{*}{ Time $^{a}$} & \multirow[t]{2}{*}{ Plaque ${ }^{b}$} & \multirow[t]{2}{*}{ Fluoride } & \multirow[t]{2}{*}{ Material } & \multicolumn{2}{|c|}{ Sucrose $^{c}$} & \multicolumn{3}{|c|}{ Lesion progression $^{\mathrm{d}}$} \\
\hline & & & & & & $n$ & $\%$ & 0 & 5 & 10 \\
\hline Benelli, 1993 & $\mathrm{P}$ & 4 & mesh & DW & $\mathrm{H}$ & 8 & 20 & 1.1 & & \\
\hline Thomas, 2007 & $\mathrm{~A}$ & 20 & NB & - & $\mathrm{H}$ & - & - & 1.1 & & \\
\hline Dijkman, 1992 & $\mathrm{~B}$ & 4 & $\mathrm{RP}$ & - & $\mathrm{H}$ & - & - & 1.2 & & \\
\hline Kielbassa, 2003 & $\mathrm{~B}$ & 4 & $\mathrm{RP}$ & - & $\mathrm{H}$ & varied & 10 & 2.0 & & \\
\hline Chimello, 2008a & $\mathrm{P}$ & 2 & mesh & $\mathrm{TP}$ & $\mathrm{H}$ & 6 & 20 & & 4.3 & \\
\hline Melo, 2013 & $\mathrm{P}$ & 2 & mesh & - & $\mathrm{B}$ & 8 & 20 & & & \\
\hline Pinto, 2009 & $\mathrm{P}$ & 2 & mesh & $\mathrm{TP}$ & $\mathrm{B}$ & 8 & 20 & & & \\
\hline Vasconcelos, 2014 & $\mathrm{P}$ & 2 & mesh & TP, DW & $\mathrm{H}$ & 8 & 20 & & & \\
\hline Pinto, 2015 & $\mathrm{P}$ & 2 & mesh & TP, DW & $\mathrm{B}$ & 8 & 20 & & & \\
\hline Wang, 2010 & $\mathrm{P}$ & 2 & mesh & - & $\mathrm{B}$ & 8 & 20 & & & \\
\hline Melo, 2014 & $\mathrm{P}$ & 2 & mesh & No & B & 8 & 20 & & & 8.8 \\
\hline
\end{tabular}

P, palatal; A, approximal; B, buccal; NB, not brushing; RP, recessed position; DW, drinking water; TP, toothpaste; H, human tooth material; $\mathrm{B}$, bovine tooth material.

a The length of time (in weeks) that the samples were worn by the participants.

$\mathrm{b}$ The plaque promotion method.

${ }^{\mathrm{c}}$ Sucrose dippings per day $(n)$ and concentration of sucrose solution (\%).

${ }^{\mathrm{d}}$ For the control group in enamel next to a composite restoration (in $\mu \mathrm{m} /$ day).

is considered an accepted alternative to human enamel in erosion research, due to its similar characteristics and properties, even though it does not resemble human enamel in all aspects [Laurance-Young et al., 2011]. A study by Fonseca et al. [2008] concluded that bovine dentin has a significantly higher radiodensity than human dentin. Currently, the comparability of human and bovine dentin is questioned more than the comparability of human and bovine enamel. Bovine dentin has significantly fewer tubules per square millimetre than human dentin, and the tubular morphology and structure are markedly different [Lopes et al., 2009]. The use of bovine dentin, as applied in 3 studies in this systematic review, can therefore be criticized [Hara et al., 2006; Reinke et al., 2012; Pinto et al., 2015].

Lesion progression after exposure to acid gel seems faster in bovine enamel than in human enamel [Edmunds et al., 1988]. This could be a partial explanation for the high lesion progression in 5 of the studies included in this review. However, there are also studies that use human enamel with similar progression rates (Fig. 3). The answer is, therefore, not clear-cut. Unfortunately, there is also no conclusive answer from the literature when it comes to the comparison of the caries process in human and bovine tooth structures [Yassen et al., 2011].
The inter-examiner reliability for the inclusion of papers based on title and abstract, was represented by a Cohen's $\kappa$ value of 0.87 . This almost perfect agreement could point to the fact that the inclusion criteria were clear and applied independently by both researchers [Landis and Koch, 1977; Wijne].

The tool developed for the quality assessment of the studies was specifically tailored to recurrent problems in in situ studies. Some difficulties arose when we applied this tool, and small changes were made along the way. The difficulties can be attributed to the fact that the tool had not been previously tested. Common problems pertaining to the risk of bias to be addressed in future studies include the reporting of the fluoride circumstances for the participants. The presence and concentration of fluoride in both toothpaste and drinking water are of interest and should be mentioned.

Study participants often had previous dental knowledge and some were affiliated with the study. This problem could be addressed by blinding the volunteers to the purpose of the study and the identity of the samples. Blinding of the analyzing researcher or statistician can also reduce the risk of bias, but this was only applied in $19 \%$ of the studies reviewed. The weighted $\kappa$ value of 0.63 between examiners using the risk of bias tool can be interpreted as "substantial" [Landis and Koch, 1977; 
Wijne], showing that the inter-observer agreement was satisfactory. Still, when interpreting the lesion progression per day values, it is valid to exercise caution, because some of these values were estimated based only on the results reported in the articles and are rather imprecise.

Many in situ models for secondary caries research have been reported and model parameters are quite variable. Differences in the plaque promotion method and the number of sucrose dippings may play a role in the rate of lesion progression. Recommendations for future studies can be formulated, regarding the design and reporting of the studies, e.g., the full reporting of fluoride exposure and increased efforts for blinding, and also the methodology, e.g., using microradiographic methods for the analysis of lesions.

\section{Acknowledgements}

This project was funded in part by a grant provided by the Foundation for the Promotion of Dental Knowledge (Stichting Bevordering Tandheelkundige Kennis), The Netherlands. The funders had no role in study design, data collection and analysis, decision to publish, or preparation of the manuscript.

\section{Disclosure Statement}

The authors declare no conflicts of interest with respect to the authorship and/or publication of this article.

\section{Author Contributions}

Conceived and designed the study: A.C.C.H., N.K.K., M.C.D.N.J.M.H. Inclusion of studies: A.C.C.H., N.K.K.. Data collection: A.C.C.H., T.T.M. Wrote the paper: A.C.C.H., N.K.K., T.T.M., M.-C.D.N.J.M.H.

\section{References}

Askar H, Tu YK, Paris S, Yeh YC, Schwendicke F: Risk of caries adjacent to different restoration materials: systematic review of in situ studies. J Dent 2017;56:1-10.

Barata JS, Casagrande L, Pitoni CM, De Araujo FB, Garcia-Godoy F, Groismann S: Influence of gaps in adhesive restorations in the development of secondary caries lesions: an in situ evaluation. Am J Dent 2012;25:244-248.

Benelli EM, Serra MC, Rodrigues AL Jr, Cury JA: In situ anticariogenic potential of glass ionomer cement. Caries Res 1993;27:280-284.

Bernardo M, Luis H, Martin MD, Leroux BG, Rue T, Leitao J, DeRouen TA: Survival and reasons for failure of amalgam versus composite posterior restorations placed in a randomized clinical trial. J Am Dent Assoc 2007;138:775783.

Cenci MS, Tenuta LM, Pereira-Cenci T, Del Bel Cury AA, ten Cate JM, Cury JA: Effect of microleakage and fluoride on enamel-dentine demineralization around restorations. Caries Res 2008;42:369-379.

Centre for Reviews and Dissemination: CRD's Guidance for Undertaking Reviews in Healthcare. York, CRD, 2008.

Chimello DT, Serra MC, Rodrigues-Junior AL, Pecora JD, Corona SA: Influence of Er:YAG laser on microhardness of enamel adjacent to restorations submitted to cariogenic challenge in situ. Photomed Laser Surg 2008a;26: 379-385.
Chimello DT, Serra MC, Rodrigues AL Jr, Pecora JD, Corona SA: Influence of cavity preparation with Er:YAG laser on enamel adjacent to restorations submitted to cariogenic challenge in situ: a polarized light microscopic analysis. Lasers Surg Med 2008b;40:634-643.

Colucci V, de Souza Gabriel AE, Scatolin RS, Serra MC, Corona SA: Effect of Er:YAG laser on enamel demineralization around restorations. Lasers Med Sci 2015;30:1175-1181.

da Silva BM, Franca FM, Florio FM, Basting RT: In situ anticariogenic effect of adhesive systems containing fluoride and MDPB. Am J Dent 2010;23:75-80.

de Moraes MD, de Melo MA, Bezerra Dda S, Costa LS, Saboia Vde P, Rodrigues LK: Clinical study of the caries-preventive effect of resinmodified glass ionomer restorations: aging versus the influence of fluoride dentifrice. J Investig Clin Dent 2016;7:180-186.

Dijkman GE, Arends J: Secondary caries in situ around fluoride-releasing light-curing composites: a quantitative model investigation on four materials with a fluoride content between 0 and $26 \mathrm{vol} \%$. Caries Res 1992;26:351357.

Edmunds DH, Whittaker DK, Green RM: Suitability of human, bovine, equine, and ovine tooth enamel for studies of artificial bacterial carious lesions. Caries Res 1988;22:327-336.

Featherstone JD, ten Cate JM, Shariati M, Arends $\mathrm{J}$ : Comparison of artificial caries-like lesions by quantitative microradiography and microhardness profiles. Caries Res 1983;17:385391.
Fejerskov O, Kidd EA: Dental Caries: The Disease and Its Clinical Management. Wiley-Blackwell, 2015, p 201.

Fonseca RB, Haiter-Neto F, Carlo HL, Soares CJ, Sinhoreti MA, Puppin-Rontani RM, CorrerSobrinho L: Radiodensity and hardness of enamel and dentin of human and bovine teeth, varying bovine teeth age. Arch Oral Biol 2008;53:1023-1029.

Grossman ES, Matejka JM: Amalgam restoration and in vitro caries formation. J Prosthet Dent 1995;73:199-209.

Hals E, Nernaes A: Histopathology of in vitro caries developing around silver amalgam fillings. Caries Res 1971;5:58-77.

Hara AT, Turssi CP, Ando M, Gonzalez-Cabezas C, Zero DT, Rodrigues AL Jr, Serra MC, Cury JA: Influence of fluoride-releasing restorative material on root dentine secondary caries in situ. Caries Res 2006;40:435-439.

Jorge AC, Cassoni A, de Freitas PM, Reis AF, Brugnera Junior A, Rodrigues JA: Influence of cavity preparation with Er,Cr:YSGG laser and restorative materials on in situ secondary caries development. Photomed Laser Surg 2015; 33:98-103.

Kielbassa AM, Muller U, Garcia-Godoy F: In situ study on the caries-preventive effects of fluoride-releasing materials. Am J Dent 1999a; 12(Spec No):S13-S14.

Kielbassa AM, Schulte-Monting J, Garcia-Godoy F, Meyer-Lueckel H: Initial in situ secondary caries formation: effect of various fluoridecontaining restorative materials. Oper Dent 2003;28:765-772. 
Kielbassa AM, Wrbas KT, Schulte-Monting J, Hellwig E: Correlation of transversal microradiography and microhardness on in situ-induced demineralization in irradiated and nonirradiated human dental enamel. Arch Oral Biol 1999b;44:243-251.

Kirsten GA, Rached RN, Mazur RF, Vieira S, Souza EM: Effect of open-sandwich vs. adhesive restorative techniques on enamel and dentine demineralization: an in situ study. J Dent 2013;41:872-880

Kuper NK, Montagner AF, van de Sande FH, Bronkhorst EM, Opdam NJ, Huysmans MC: Secondary caries development in in situ gaps next to composite and amalgam. Caries Res 2015;49:557-563.

Kuper NK, Opdam NJ, Ruben JL, de Soet JJ, Cenci MS, Bronkhorst EM, Huysmans MC: Gap size and wall lesion development next to composite. J Dent Res 2014;93:108s-113s.

Landis JR, Koch GG: The measurement of observer agreement for categorical data. Biometrics 1977;33:159-174.

Laurance-Young P, Bozec L, Gracia L, Rees G, Lippert F, Lynch RJ, Knowles JC: A review of the structure of human and bovine dental hard tissues and their physicochemical behaviour in relation to erosive challenge and remineralisation. J Dent 2011;39:266-272.

Lennon AM, Wiegand A, Buchalla W, Attin T: Approximal caries development in surfaces in contact with fluoride-releasing and non-fluoride-releasing restorative materials: an in situ study. Eur J Oral Sci 2007;115:497-501.

Lima FG, Romano AR, Correa MB, Demarco FF: Influence of microleakage, surface roughness and biofilm control on secondary caries formation around composite resin restorations: an in situ evaluation. J Appl Oral Sci 2009;17: 61-65.

Lopes MB, Sinhoreti MA, Gonini Junior A, Consani S, McCabe JF: Comparative study of tubular diameter and quantity for human and bovine dentin at different depths. Braz Dent J 2009;20:279-283.

Lynch RJ, ten Cate JM: Effect of calcium glycerophosphate on demineralization in an in vitro biofilm model. Caries Res 2006;40:142-147.
Magalhaes AC, Moron BM, Comar LP, Wiegand A, Buchalla W, Buzalaf MA: Comparison of cross-sectional hardness and transverse microradiography of artificial carious enamel lesions induced by different demineralising solutions and gels. Caries Res 2009;43:474-483.

Melo MA, Codes BM, Passos VF, Lima JP, Rodrigues LK: In situ response of nanostructured hybrid fluoridated restorative composites on enamel demineralization, surface roughness and ion release. Eur J Prosthodont Restor Dent 2014;22:185-190.

Melo MA, Weir MD, Rodrigues LK, Xu HH: Novel calcium phosphate nanocomposite with caries-inhibition in a human in situ model. Dent Mater 2013;29:231-240.

Montagner AF, Kuper NK, Opdam NJ, Bronkhorst EM, Cenci MS, Huysmans MC: Walllesion development in gaps: the role of the adhesive bonding material. J Dent 2015;43: 1007-1012.

Moura JS, Lima EM, Paes Leme AF, Del Bel Cury AA, Tabchoury CP, Cury JA: Effect of luting cement on dental biofilm composition and secondary caries around metallic restorations in situ. Oper Dent 2004;29:509-514.

Paradella TC, Koga-Ito CY, Jorge AO: Ability of different restorative materials to prevent in situ secondary caries: analysis by polarized light-microscopy and energy-dispersive Xray. Eur J Oral Sci 2008;116:375-380.

Pinto CF, Berger SB, Cavalli V, Da Cruz SE, Goncalves RB, Ambrosano GM, Giannini M: In situ antimicrobial activity and inhibition of secondary caries of self-etching adhesives containing an antibacterial agent and/or fluoride. Am J Dent 2015;28:167-173.

Pinto CF, Paes Leme AF, Ambrosano GM, Giannini M: Effect of a fluoride- and bromidecontaining adhesive system on enamel around composite restorations under high cariogenic challenge in situ. J Adhes Dent 2009;11:293-297.

Reinke SMG, De Campos Lawder JA, Divardin S, Raggio D, Reis A, Loguercio AD: Degradation of the resin-dentin bonds after simulated and inhibited cariogenic challenge in an in situ model. J Biomed Mater Res B Appl Biomater 2012;100B:1466-1471.
Sousa RP, Zanin ICJ, Lima JPM, Vasconcelos SMLC, Melo MAS, Beltrao HCP, Rodrigues LKA: In situ effects of restorative materials on dental biofilm and enamel demineralisation. J Dent 2009;37:44-51.

The Cochrane Collaboration: The Cochrane Collaboration's tool for assessing risk of bias; in Higgins J, Green S (eds): Cochrane Handbook for Systematic Reviews of Interventions. Internet (updated 2011).

Thomas RZ, Ruben JL, de Vries J, ten Bosch JJ, Huysmans MC: Transversal wavelength-independent microradiography, a method for monitoring caries lesions over time, validated with transversal microradiography. Caries Res 2006;40:281-291.

Thomas RZ, Ruben JL, ten Bosch JJ, Fidler V, Huysmans MC: Approximal secondary caries lesion progression, a 20 -week in situ study. Caries Res 2007;41:399-405.

van de Sande FH, Opdam NJ, Truin GJ, Bronkhorst EM, de Soet JJ, Cenci MS, Huysmans MC: The influence of different restorative materials on secondary caries development in situ. J Dent 2014;42:1171-1177.

Vasconcelos SM, Melo MA, Wenceslau JP, Zanin IC, Beltrao HC, Fernandes CA, Almeida PC, Rodrigues LK: In situ assessment of effects of the bromide- and fluoride-incorporating adhesive systems on biofilm and secondary caries. J Contemp Dent Pract 2014;15:142-148.

Vellini-Ferreira F, Cotrim-Ferreira FA, Ribeiro JA, Ferreira-Santos RI: Mapping of proximal enamel thickness in permanent teeth. Braz J Oral Sci 2012;11:481-485.

Wang L, Honorio HM, Rios D, Delbem AC, PalmaDibb RG, Buzalaf MA, Atta MT, Tenuta LM: Short-term in situ/ex vivo study of the anticariogenic potential of a resin-modified glass-ionomer cement associated with adhesive systems. Quintessence Int 2010;41:e192-e199.

Wijne HJ: Kennisbasis Statistiek: Cohen's kappa. http://www.wynneconsult.com/root/Assoc/ Cohe336.htm.

Yassen GH, Platt JA, Hara AT: Bovine teeth as substitute for human teeth in dental research: a review of literature. J Oral Sci 2011;53:273282 